\title{
National survey on intra-laboratory turnaround time for some most common routine and stat laboratory analyses in $\mathbf{4 7 9}$ laboratories in China
}

\author{
Yang Fei, Rong Zeng, Wei Wang, Falin He, Kun Zhong, Zhiguo Wang* \\ Authors Yang Fei and Rong Zeng contributed equally to this work. \\ National Center for Clinical Laboratories, Beijing Hospital, Beijing, P.R. China \\ ${ }^{*}$ Corresponding author: zgwang@nccl.org.cn
}

\begin{abstract}
Introduction: To investigate the state of the art of intra-laboratory turnaround time (intra-TAT), provide suggestions and find out whether laboratories accredited by International Organization for Standardization (ISO) 15189 or College of American Pathologists (CAP) will show better performance on intra-TAT than non-accredited ones.
\end{abstract}

Materials and methods: 479 Chinese clinical laboratories participating in the external quality assessment programs of chemistry, blood gas, and haematology tests organized by the National Centre for Clinical Laboratories in China were included in our study. General information and the median of intra-TAT of routine and stat tests in last one week were asked in the questionnaires.

Results: The response rate of clinical biochemistry, blood gas, and haematology testing were 36\% (479 / 1307), 38\% (228 / 598), and 36\% (449 / 1250), respectively. More than $50 \%$ of laboratories indicated that they had set up intra-TAT median goals and almost $60 \%$ of laboratories declared they had monitored intra-TAT generally for every analyte they performed. Among all analytes we investigated, the intra-TAT of haematology analytes was shorter than biochemistry while the intra-TAT of blood gas analytes was the shortest. There were significant differences between median intra-TAT on different days of the week for routine tests. However, there were no significant differences in median intra-TAT reported by accredited laboratories and non-accredited laboratories.

Conclusions: Many laboratories in China are aware of intra-TAT control and are making effort to reach the target. There is still space for improvement. Accredited laboratories have better status on intra-TAT monitoring and target setting than the non-accredited, but there are no significant differences in median intra-TAT reported by them.

Key words: quality indicators; quality control; clinical laboratory services

\section{Introduction}

Quality can be defined as the ability of a product or service to satisfy the needs and expectations of the customer. Laboratories are focusing more on technical and analytical quality for the reliability and accuracy of test results. Patients and clinicians, however, are interested in rapid, reliable and efficient service from clinical laboratories (1). Turnaround time (TAT), the timeliness with which laboratory personnel deliver test results, is one of the most noticeable quality indicators and often used as a key performance indicator of laboratory performance. Certain studies suggest that the TAT of laboratory tests directly has the influences on: du- ration of stay of patients in the emergency department (ED), i.e. reduction of laboratory TAT shortens ED stay, and enhancing the safety and satisfaction of patients (2-4).

International health-care regulatory agencies, including International Standardization Organization (ISO) 15189:2012 (5), have set requirements on timeliness of test results. In China, the National Health and Family Planning Commission (the former Ministry of Health) also issued the Regulation on clinical laboratory of medical organization and the Evaluation standards for tertiary general hospitals in 2006 and 2011, respectively $(6,7)$. These 
two documents have improved the timeliness of test results delivering all over China. At the same time, the laboratory accreditation program proposed by College of American Pathologists (CAP) has taken TAT as a quantitative quality indicator to determine the timeliness of test results (8). Thus, several cross-sectional studies on TAT have been carried out in America and related improvement measures have been proposed. In 2008, International Federation of Clinical Chemistry (IFCC) set up a working group named "Laboratory Errors and Patient Safety". The group has developed the preliminary model of quality indicators, which also includes the monitoring of TAT (9). Pre-analytical and post-analytical phases were beyond the control of the clinical laboratories and only a few laboratories in China were monitoring pre-analytical and postanalytical TAT in their daily work. Time taken from the receipt of a specimen in the laboratory to the time of reporting of the test result was chosen to study on in this investigation. This definition is also known as "intra-laboratory turnaround time" (intraTAT) which is generally under the direct control of the laboratory and is an index of its efficiency.

Nowadays, when more and more laboratories in China have been accredited by ISO 15189 or CAP, we were wondering whether these laboratories would show better performance on intra-TAT than non-accredited ones. We also wanted to know the intra-TAT tendency during one week to find out the day of week on which we should focus more. There aren't any national intra-TAT quality specifications in China at present and the overall situation of intra-TAT monitoring in China is still unknown. Therefore, we carried out a national investigation on intra-TAT for routine and stat test of biochemistry, blood gas and haematology analytes in different laboratories, in 2011 in China, with hoping to solve these problems.

\section{Material and methods}

\section{Study design}

Clinical laboratories from different provinces in China, which participated in the Chinese external quality assessment (EQA) programs, organized by the National Centre for Clinical Laboratories (NCCL) in 2011, were included in the study, which was initiated in March of 2011, Beijing, China. Blood banks, centres for disease control and prevention, private laboratories and independent commercial laboratories were excluded. There were three sets of questionnaires for clinical laboratories which participated in different EQA: biochemistry intraTAT questionnaire, blood gas intra-TAT questionnaire and haematology intra-TAT questionnaire. 1307 clinical laboratories which participated in the EQA programs of routine chemistry, cardiac biomarker, and $\mathrm{N}$-terminal pro-brain natriuremic peptide (NT-pro-BNP) were asked to complete the questionnaire of biochemistry intra-TAT. 598 clinical laboratories in the EQA program of blood gas were requested to fill in the questionnaire of blood gas intra-TAT. Additionally, 1250 clinical laboratories in the complete blood count (CBC) and coagulation EQA programs were required to finish the questionnaire of haematology intra-TAT.

\section{Survey}

All questionnaires were divided in two parts. The first part was about the general information of participants, including the demographic data of the hospital and monitoring status of intra-TAT (Table 1). The second part aimed to collect information on the total number of specimens and the median intra-TAT for both the routine and stat tests of biochemistry, blood gas and haematology analytes. Median intra-TAT for all the samples on each day from Sunday to Saturday was also collected. Laboratories were asked to submit the questionnaires within 1 week after receiving it. Nine tests were provided in the questionnaire of routine tests for biochemistry analytes, and four tests were included in the questionnaire of stat tests for biochemistry analytes. The investigation for blood gas analytes chose $\mathrm{pH}$ as representative. Finally, questionnaire on haematology included three tests. Compositions of second part of questionnaire were shown in Table 2. Stat analytes were tests ordered when the results were in urgent need, typically for patients from emergency department, outpatient with serious diseases, intensive care unit (ICU) patients whose condition change suddenly, and inpatients with serious diseases or whose condition change suddenly. 
TABLE 1. Questions and answers for the general information and intra-TAT monitoring practice of clinical laboratory.

\begin{tabular}{|c|c|c|c|}
\hline Questions and possible answers & $\begin{array}{c}\text { Biochemistry } \\
\% \text { (N / total) }\end{array}$ & $\begin{array}{c}\text { Blood gas } \\
\% \text { (N / total) }\end{array}$ & $\begin{array}{c}\text { Haematology } \\
\% \text { (N / total) }\end{array}$ \\
\hline \multicolumn{4}{|l|}{ 1. What is your hospital type? } \\
\hline A. tertiary hospital & $78(375$ / 479) & $86(196 / 228)$ & $78(351$ / 449) \\
\hline B. secondary hospital & $19(89$ / 479) & $13(30 / 228)$ & $18(80$ / 449) \\
\hline C. primary hospital & $1(6 / 479)$ & $0(0 / 288)$ & $2(10$ / 449) \\
\hline Unclear & $2(9 / 479)$ & $1(2 / 288)$ & $2(8 / 449)$ \\
\hline \multicolumn{4}{|l|}{ 2. What is your hospital category? } \\
\hline A. general hospital & $76(366$ / 479) & $84(192$ / 228) & $78(352$ / 449) \\
\hline B. traditional Chinese medicine hospitals & $7(35$ / 479) & $5(11 / 228)$ & $6(28$ / 449) \\
\hline C. maternal and child-care service centres & $5(24$ / 479) & $3(6 / 228)$ & $4(19$ / 449) \\
\hline D. hospitals specializing on tumour treatment & $3(13$ / 479) & $3(7 / 228)$ & $3(15$ / 449) \\
\hline E. children's hospitals & $2(9 / 479)$ & $2(5 / 228)$ & $3(12$ / 449) \\
\hline F. obstetrical and gynaecological hospitals & $1(5 / 479)$ & $0(0 / 228)$ & $1(4 / 449)$ \\
\hline G. others & $4(18$ / 479) & $1(3 / 228)$ & $1(6 / 449)$ \\
\hline Unclear & $2(9 / 479)$ & $2(4 / 228)$ & $3(13$ / 449) \\
\hline \multicolumn{4}{|c|}{ 3. Has your laboratory been accredited by ISO 15189 or CAP? } \\
\hline A. Yes & $17(80$ / 479) & $20(46 / 228)$ & $16(71 / 449)$ \\
\hline B. No & $81(390$ / 479) & $79(179 / 228)$ & $83(371$ / 449) \\
\hline Unclear & $2(9$ / 479) & $1(3 / 228)$ & $2(7 / 449)$ \\
\hline \multicolumn{4}{|c|}{ 4. Is laboratory information system employed in your laboratory? } \\
\hline A. Yes & $85(405$ / 479) & $90(205 / 228)$ & $85(383$ / 449) \\
\hline B. No & $15(74$ / 479) & $9(21 / 228)$ & $14(64$ / 449) \\
\hline Unclear & $2(8 / 479)$ & $1(2 / 228)$ & $0(2 / 449)$ \\
\hline \multicolumn{4}{|l|}{ 5. Is barcode system used in your laboratory? } \\
\hline A. Yes & $66(318$ / 479) & $75(170$ / 228) & $67(299$ / 449) \\
\hline B. No & $32(153$ / 479) & $25(56 / 228)$ & $32(145$ / 449) \\
\hline Unclear & $2(8 / 479)$ & $1(2 / 228)$ & $1(5 / 449)$ \\
\hline \multicolumn{4}{|c|}{ 6. Has your institution set up a target intra-TAT median for every analyte you performed? } \\
\hline A. Yes & $53(257$ / 479) & $57(131 / 228)$ & $59(263$ / 449) \\
\hline B. No & $45(215 / 479$ & $39(90 / 228)$ & $41(186 / 449)$ \\
\hline Unclear & $1(7 / 479)$ & $3(7 / 228)$ & $0(0 / 449)$ \\
\hline \multicolumn{4}{|c|}{ 7. Is your laboratory monitoring intra-TAT generally? } \\
\hline A. Yes & $59(283$ / 479) & $61(140 / 228)$ & $61(273$ / 449) \\
\hline B. No & $38(180$ / 479) & $34(77 / 228)$ & $38(171$ / 449) \\
\hline Unclear & $3(16 / 479)$ & $5(11 / 228)$ & $1(5 / 449)$ \\
\hline
\end{tabular}

intra-TAT - intra-laboratory turnaround time; ISO - international organization for standardization; CAP - College of American Pathologists 
TABLE 2. Analytes that were the subjects of questionnaire data for TAT.

\begin{tabular}{cc}
\hline Category & Analytes \\
\hline Routine biochemistry analyte & $\mathrm{K}, \mathrm{Glu}, \mathrm{TP}, \mathrm{ALT}, \mathrm{TIBC}, \mathrm{Mg}, \mathrm{TG}$, \\
CK-MB, cTnl & $\mathrm{K}, \mathrm{Glu}, \mathrm{CK}-\mathrm{MB}, \mathrm{AMY}$ \\
Rout biochemistry analyte & $\mathrm{pH}$ \\
Stat blood gas analyte & $\mathrm{pH}$ \\
Routine haematology analyte & $\mathrm{WBC}, \mathrm{PT}, \mathrm{Fbg}$ \\
Stat haematology analyte & WBC, PT, Fbg \\
\hline
\end{tabular}

TAT - turnaround time; $\mathrm{K}$ - potassium; Glu - glucose; TP - total protein; ALT - alanine aminotransferase; TIBC - total iron binding capacity; Mg - magnesium; TG - triglyceride; CK-MB - creatine kinase-MB; cTnl - troponin I; AMY - amylase; WBC - white blood cell; PT -prothrombin time; Fbg - fibrinogen.

\section{Data collection}

All laboratories were informed of the EQA program of intra-TAT investigation. Laboratories were advised to collect intra-TAT with the use of LIS (laboratory informative system). Those which did not have LIS may collect intra-TAT manually. This EQA program of intra-TAT investigation was totally free of charge. There were three ways for submitting their questionnaire. The mostly recommended way was to submit information via online EQA platform for intra-TAT developed by the NCCL (www.clinet.com.cn) (10). E-mail and regular mails were also accepted.

\section{Statistical methods}

All collected data were analyzed via special statistical software designed by NCCL and developed by the Clinet information technology (Beijing, China) and SPSS 13.0 (SPSS Inc., Chicago, IL, USA). The distribution of TAT data was non-Gaussian (11). Data were presented as median, and the 10th and the 90th percentiles. Mann-Whitney $U$ test was launched to test the differences between intra-TAT of routine and stat tests as well as the differences between intra-TAT reported by laboratories accredited by ISO 15189 or CAP and the non-accredited ones in some certain representative biochemistry analytes. Kruskal-Wallis test was employed to look into the intra-TAT on different days of one week. Chi-square test was used to test the differences between laboratories accredited by ISO 15189 or CAP and non-accredited ones in intra-TAT monitoring practice. $\mathrm{P} \leq 0.05$ was defined as the threshold of significance.

\section{Results}

There were 479, 238 and 449 questionnaires returned for intra-TAT in biochemistry, blood gas, and haematology, respectively. Thus, the response rates for the three questionnaires were $36 \%$ (479 / 1307), 38\% (228 / 598), and 36\% (449 / 1250), respectively.

General information of participant laboratories and monitoring status of intra-TAT were shown in Table 1. The major hospitals involved in this study were tertiary hospitals with a percentage of $78 \%$ (375 / 479), 86\% (196 / 228), and 78\% (351 / 449) for biochemistry, blood gas, and haematology tests, respectively. Less than $20 \%$ of the laboratories were accredited by ISO 15189 or CAP, which were $17 \%$ (80 / 479), 20\% (46 / 228) and 16\% (71 / 449) for biochemistry, blood gas, and haematology tests, respectively. 84\% (405 / 479), 90\% (205 / 228), and $85 \%$ (383 / 449) of laboratories employed LIS and 66\% (318 / 479), 75\% (170 / 228) and 67\% (299 / 449) of the participants used the barcode system to ensure the accuracy and timeliness of the transmission and report of the results of biochemistry, blood gas, and haematology tests. More than $50 \%$ of the laboratories indicated that they had set up a target intra-TAT median for each analyte they dealt with and monitoring intra-TAT generally.

\section{The intra-TAT of routine and stat tests}

\section{Biochemistry analytes}

The median intra-TAT of routine biochemistry tests varied among different analytes. Total iron-binding capacity (TIBC's) median intra-TAT (180.0 min) was the highest, while cardiac troponin I (cTnl's) median intra-TAT $(97.0 \mathrm{~min})$ was the shortest, among all routine biochemistry tests. However, the median of intra-TATs of stat biochemistry tests were similar (43.0 $\mathrm{min}, 45.0 \mathrm{~min}, 45.0 \mathrm{~min}$, and 45.0 
min for potassium $(K)$, glucose $(\mathrm{Glu})$, creatine kinase $M B(C K-M B)$, and amylase (AMY), respectively) and significantly shorter than each of the routine tests, as shown in Table 3 and Table 4.

\section{Blood gas analytes}

The median intra-TATs for routine and stat $\mathrm{pH}$ were $15.5 \mathrm{~min}$ and $14.3 \mathrm{~min}$, respectively. The median intra-TATs for almost all participants were less than $60.0 \mathrm{~min}$. Only three participants reported higher
intra-TATs, first one $369.1 \mathrm{~min}$, second one 114.4 $\mathrm{min}$ and third one $82.6 \mathrm{~min}$.

\section{Haematology analytes}

As we can see, the median intra-TAT of white blood count (WBC) (44.7 min) was shorter than those of the other two analytes $(85.0 \mathrm{~min}$ and $88.0 \mathrm{~min}$ for prothrombin time (PT) and fibrinogen (Fbg), respectively). Also, the median intra-TATs of stat tests were significantly shorter than that of routine tests. For details see Table 3 and Table 4.

TABLE 3. Median intra-TAT of routine and stat analytes (min).

\begin{tabular}{|c|c|c|c|c|c|}
\hline $\begin{array}{l}\text { Category and } \\
\text { analytes }\end{array}$ & $\begin{array}{l}\text { Number of } \\
\text { laboratories }\end{array}$ & $\begin{array}{l}\text { Total number of specimens in a week } \\
\text { in different labs [median (10th,90th)] }\end{array}$ & $\begin{array}{c}\text { Median } \\
\text { (min) }\end{array}$ & $\begin{array}{l}1^{\text {th }} \text { percentile } \\
\text { (min) }\end{array}$ & $\begin{array}{l}90^{\text {th }} \text { percentile } \\
\text { (min) }\end{array}$ \\
\hline \multicolumn{6}{|c|}{ Routine biochemistry analyte } \\
\hline K & 321 & $714(210,2250)$ & 136.0 & 51.2 & 349.0 \\
\hline Glu & 320 & $1043(302,2979)$ & 130.0 & 59.5 & 349.5 \\
\hline TP & 311 & $1000(334,3100)$ & 158.5 & 62.9 & 352.0 \\
\hline ALT & 311 & $1200(389,2003)$ & 151.0 & 70.0 & 350.0 \\
\hline TIBC & 93 & $54(7,1099)$ & 180.0 & 60.0 & 360.0 \\
\hline $\mathrm{Mg}$ & 276 & $427(48,1809)$ & 152.5 & 60.0 & 350.0 \\
\hline TG & 307 & $705(180,2194)$ & 160.0 & 70.0 & 350.0 \\
\hline CK-MB & 271 & $251(40,1092)$ & 122.0 & 50.4 & 327.6 \\
\hline cTnl & 189 & $72(14,433)$ & 97.0 & 37.65 & 300.0 \\
\hline \multicolumn{6}{|c|}{ Stat biochemistry analyte } \\
\hline K & 316 & $180(35,1047)$ & 43.0 & 25.0 & 80.0 \\
\hline Glu & 314 & $150(30,797)$ & 45.0 & 21.8 & 80.3 \\
\hline CK-MB & 268 & $70(15,384)$ & 45.0 & 27.4 & 80.0 \\
\hline AMY & 298 & $60(11,337)$ & 45.0 & 26.0 & 80.0 \\
\hline \multicolumn{6}{|c|}{ Routine blood gas analyte } \\
\hline $\mathrm{pH}$ & 162 & $80(20,300)$ & 15.5 & 5.0 & 37.4 \\
\hline \multicolumn{6}{|c|}{ Stat blood gas analyte } \\
\hline $\mathrm{pH}$ & 181 & $56(10,224)$ & 14.3 & 5.0 & 30.0 \\
\hline \multicolumn{6}{|c|}{ Routine haematology analyte } \\
\hline WBC & 319 & $1400(451,4081)$ & 44.7 & 17.0 & 185.0 \\
\hline PT & 317 & $404(140,1145)$ & 85.0 & 35.0 & 204.2 \\
\hline Fbg & 311 & $400(136,1041)$ & 88.0 & 37.20 & 209.0 \\
\hline \multicolumn{6}{|c|}{ Stat haematology analyte } \\
\hline WBC & 314 & $300(63,1400)$ & 20.0 & 9.0 & 40.0 \\
\hline PT & 316 & $98(12,388)$ & 40.0 & 22.0 & 60.0 \\
\hline $\mathrm{Fbg}$ & 309 & $95(20,350)$ & 40.0 & 22.9 & 63.0 \\
\hline
\end{tabular}

intra-TAT - intra-laboratory turnaround time; K - potassium; Glu - glucose; TP - total protein; ALT - alanine aminotransferase; TIBC - total iron binding capacity; Mg - magnesium; TG - triglyceride; CK-MB - creatine kinase-MB; CTnl - troponin I; AMY - amylase; WBC white blood cell; PT - prothrombin time; Fbg - fibrinogen. 
TABLE 4. Comparison of intra-TAT of routine and stat tests for different analytes

\begin{tabular}{ccc}
\hline Analytes & $\mathbf{Z}$ & P value \\
\hline $\mathrm{K}$ & -13.71 & $<\mathbf{0 . 0 0 1}$ \\
Glu & -16.92 & $<\mathbf{0 . 0 0 1}$ \\
CK-MB & -9.68 & $<\mathbf{0 . 0 0 1}$ \\
pH & -3.00 & $\mathbf{0 . 0 0 3}$ \\
WBC & -15.67 & $<\mathbf{0 . 0 0 1}$ \\
PT & -15.68 & $<\mathbf{0 . 0 0 1}$ \\
Fbg & -15.54 & $<\mathbf{0 . 0 0 1}$ \\
\hline
\end{tabular}

intra-TAT - intra-laboratory turnaround time; K - potassium; Glu - glucose; CK-MB - creatine kinase-MB; WBC - white blood cell; PT - prothrombin time; Fbg - fibrinogen.

Mann-Whitney $U$ test with a $P$ value of $\leq 0.05$ considered significant was used to test the differences between intra-TAT of routine and stat tests for different analytes.

\section{Comparison of accredited and non-accredited laboratories}

As there were more accredited laboratories (80) involved in biochemistry surveys, we chose biochemistry surveys as the representative. As we can see, the frequency of laboratory using LIS ( $P=$ $0.012)$ or barcode system $(P=0.004)$ in accredited laboratories was significantly higher than in nonaccredited laboratories. And there were more laboratories which had defined a target median intraTAT for all analyses $(P<0.001)$ or which were monitoring intra-TAT generally $(P<0.001)$ in accredited laboratories. However, there were no significant differences between median intra-TAT reported by accredited laboratories and non-accredited ones for routine $K(P=0.572)$, routine $C K-M B(P=0.516)$, routine TIBC $(P=0.749)$, stat $K(P=0.789)$, and stat CK-MB $(P=0.592)$. All others data are shown in Table 5 .

TABLE 5. Comparison between laboratories which have been accredited by ISO 15189 or CAP and non-accredited laboratories in median intra-TAT ( $\mathrm{min}$ ) and their monitoring practice for biochemistry survey.

\begin{tabular}{|c|c|c|c|}
\hline Items & $\begin{array}{l}\text { Laboratories have been } \\
\text { accredited by ISO } 15189 \text { or CAP }\end{array}$ & $\begin{array}{l}\text { Non-accredited } \\
\text { laboratories }\end{array}$ & P value \\
\hline $\begin{array}{l}\text { Frequency of laboratory using laboratory information } \\
\text { system }(\%, \mathrm{~N} / \text { total) }\end{array}$ & $94(75 / 80)$ & $83(322$ / 390) & $0.012^{a}$ \\
\hline $\begin{array}{l}\text { Frequency of laboratory using barcode system (\%, N / } \\
\text { total) }\end{array}$ & $80(64 / 80)$ & $63(247$ / 390) & $0.004^{a}$ \\
\hline $\begin{array}{l}\text { Frequency of laboratories which have defined a target } \\
\text { median intra-TAT for all analyses (\%, N / total) }\end{array}$ & $71(57 / 80)$ & $49(192 / 390)$ & $<0.001^{\mathrm{a}}$ \\
\hline $\begin{array}{l}\text { Frequency of laboratories which were monitoring } \\
\text { intra-TAT generally }(\%, \mathrm{~N} / \text { total) }\end{array}$ & $90(72$ / 80) & $52(204 / 390)$ & $<0.001^{\mathrm{a}}$ \\
\hline Median intra-TAT for routine $\mathrm{K}$ [median $\left.\left(10^{\text {th }}, 90^{\text {th }}\right)\right](\mathrm{min})$ & $128.0(50.0,348.6)$ & $136.0(52.4,332.0)$ & $0.572^{b}$ \\
\hline $\begin{array}{l}\left.\text { Median intra-TAT for routine CK-MB [median }\left(10^{\text {th }}, 90^{\text {th }}\right)\right] \\
(\min )\end{array}$ & $115.0(54.0,310.0)$ & $126.0(48.8,312.2)$ & $0.516^{\mathrm{b}}$ \\
\hline $\begin{array}{l}\text { Median intra-TAT for routine TIBC }\left[\text { median }\left(10^{\text {th }}, 90^{\text {th }}\right)\right] \\
(\min )\end{array}$ & $159.5(66.5,354.0)$ & $180.0(58.2,354.5)$ & $0.749^{b}$ \\
\hline Median intra-TAT for stat K [median $\left.\left(10^{\text {th }}, 90^{\text {th }}\right)\right]$ (min) & $43.0(22.6,80.8)$ & $43.0(21.0,81.3)$ & $0.789^{b}$ \\
\hline Median intra-TAT for stat CK-MB [median $\left.\left(10^{\text {th }}, 90^{\text {th }}\right)\right]$ (min) & $45.0(27.8,76.5)$ & $45.0(27.2,81.0)$ & $0.592^{b}$ \\
\hline
\end{tabular}

intra-TAT - intra-laboratory turnaround time; ISO - international organization for standardization; CAP - College of American Pathologists; $\mathrm{K}$ - potassium; TIBC - total iron binding capacity; CK-MB - creatine kinase-MB.

${ }^{a} \mathrm{Chi}$-square test with a $\mathrm{P}$ value of $\leq 0.05$ considered significant was used to test the differences between laboratories accredited by ISO 15189 or CAP and non-accredited laboratories.

bMann-Whitney $U$ test with a $P$ value of $\leq 0.05$ considered significant was used to test the differences between intra-TAT of laboratories accredited by ISO 15189 or CAP and non-accredited laboratories. 


\section{Change tendency of intra-TAT in one week}

Daily median intra-TATs in one week for $\mathrm{K}$, Glu, CK$M B, A M Y, p H, W B C, P T$ and Fbg were shown in Table 6.

For routine tests, the median intra-TAT varied significantly on different days of the week and the median intra-TAT on workdays was much larger than that at weekend (except for $\mathrm{pH}$ ). As we can see for potassium, the median intra-TAT from Monday to Sunday were $135.0 \mathrm{~min}, 156.5 \mathrm{~min}, 140.5$ min, $134.5 \mathrm{~min}, 130.0 \mathrm{~min}, 120.0 \mathrm{~min}$ and 120.0 min, respectively. Among all the workdays, the median intra-TAT on Tuesday was the highest. Details are shown in Table 6.
However, for stat tests, there was no significant difference among median intra-TATs on different days of the week. Additionally, there was no significant difference among median intra-TATs on different days of the week in both routine and stat $\mathrm{pH}$ test.

\section{Discussion}

This is the first survey ever launched to investigate the median intra-TAT of routine and stat tests of biochemistry, blood gas and haematology analytes in different laboratories in China. The distribution of the hospitals in this study was exactly the same as that of the participants in the EQA

TABLE 6. Median intra-TAT on each day of a week for routine and stat analytes ( $\mathrm{min})$.

\begin{tabular}{|c|c|c|c|c|c|c|c|c|c|}
\hline $\begin{array}{l}\text { Category and } \\
\text { analytes }\end{array}$ & $\mathbf{N}$ & Sun & Mon & Tues & Wed & Thur & Fri & Sat & P value \\
\hline \multicolumn{10}{|c|}{ Routine biochemistry analyte } \\
\hline K & 278 & 120.0 & 135.0 & 156.5 & 140.5 & 134.5 & 130.0 & 120.0 & $<0.001$ \\
\hline Glu & 273 & 117.0 & 130.0 & 150.0 & 138.0 & 129.0 & 128.0 & 120.0 & $<0.001$ \\
\hline CK-MB & 241 & 108.0 & 125.0 & 135.0 & 131.0 & 122.0 & 120.0 & 120.0 & 0.001 \\
\hline \multicolumn{10}{|c|}{ Stat biochemistry analyte } \\
\hline K & 271 & 41.9 & 45.0 & 45.0 & 43.0 & 42.2 & 43.0 & 43.0 & 0.724 \\
\hline Glu & 266 & 45.0 & 45.0 & 49.0 & 46.5 & 45.0 & 45.0 & 45.0 & 0.366 \\
\hline CK-MB & 240 & 45.5 & 48.5 & 50.0 & 48.0 & 49.0 & 45.3 & 45.5 & 0.506 \\
\hline AMY & 255 & 45.0 & 45.0 & 50.0 & 47.0 & 45.0 & 45.0 & 45.0 & 0.547 \\
\hline \multicolumn{10}{|c|}{ Routine blood gas analyte } \\
\hline $\mathrm{pH}$ & 143 & 15.0 & 15.0 & 16.0 & 15.0 & 16.0 & 15.0 & 15.0 & 0.996 \\
\hline \multicolumn{10}{|c|}{ Stat blood gas analyte } \\
\hline $\mathrm{pH}$ & 162 & 13.5 & 14.0 & 13.5 & 13.0 & 12.5 & 13.0 & 13.5 & 0.998 \\
\hline \multicolumn{10}{|c|}{ Routine haematology analyte } \\
\hline WBC & 291 & 30.5 & 42.0 & 50.0 & 46.0 & 45.0 & 42.0 & 38.0 & $<0.001$ \\
\hline PT & 287 & 60.0 & 80.0 & 90.0 & 84.5 & 82.0 & 80.0 & 71.0 & $<0.001$ \\
\hline Fbg & 282 & 60.0 & 82.0 & 90.0 & 85.0 & 82.0 & 80.0 & 72.0 & $<0.001$ \\
\hline \multicolumn{10}{|c|}{ Stat haematology analyte } \\
\hline WBC & 284 & 20.0 & 20.0 & 21.0 & 20.0 & 20.0 & 20.0 & 20.0 & 0.054 \\
\hline PT & 284 & 38.0 & 40.0 & 40.0 & 40.0 & 40.0 & 39.0 & 38.0 & 0.089 \\
\hline $\mathrm{Fbg}$ & 277 & 39.0 & 40.0 & 40.0 & 40.0 & 40.0 & 39.0 & 38.0 & 0.070 \\
\hline
\end{tabular}

intra-TAT - intra-laboratory turnaround time; K - potassium; Glu - glucose; TP - total protein; CK-MB - creatine kinase-MB; AMY amylase; WBC - white blood cell; PT - prothrombin time; Fbg - fibrinogen; Mon - Monday; Tues - Tuesday; Wed - Wednesday; Thur Thursday; Fri - Friday; Sat - Saturday; Sun - Sunday.

Kruskal-Wallis test was employed to look into the intra-TAT on different days of one week. 
programs organized by NCCL, with more tertiary and less secondary or primary hospitals. To a certain extent, these hospitals represented the good performance of laboratories in China.

Many participants indicated they had set up a target intra-TAT median for every analyte they dealt with and declared they had monitored it generally. This means that the majority of the participant laboratories had the awareness of intra-TAT control and that they were making effort to reach the target.

The median intra-TATs of the routine test varied among different analytes and different days of a week. There were three major reasons. Firstly, laboratory staff usually pays more attention on tests which tend to be emergent, so median intra-TAT of cTnl was shortest than other biochemistry analytes while median intra-TAT of $\mathrm{pH}$ was the shortest among all analytes in this survey. Secondly, the complexity and time-consuming nature of the measurement methods may affect intra-TAT largely, so the median intra-TAT of WBC was apparently shorter than that of coagulation tests and median intra-TAT of haematology analytes was shorter than that of biochemistry. Finally, the number of samples may influence intra-TAT obviously. As we can see, the median intra-TAT varied significantly on different days of the week for routine tests and the median intra-TAT on Tuesday was the longest. The reason for that probably lies in the number of samples which was the highest on Tuesday in many hospitals in China. Therefore, more laboratory staff should be included on Tuesday to provide high quality services. Clinical laboratories can shorten intra-TAT by employing advanced planning systems and time-saving measurement methods as well as including more labour and instruments to deal with specimens at rush hours.

In this survey, accredited laboratories had better status on intra-TAT monitoring and target setting than the non-accredited. Additionally, the frequency of laboratories using LIS or barcode system in accredited laboratories was significantly higher than in non-accredited ones. We predicted that accredited laboratories would get better performance on intra-TAT than non-accredited labo- ratories. However, there were no significant differences in median intra-TAT reported by accredited laboratories and non-accredited laboratories. Namely, majority of the participant laboratories in this survey were from tertiary and general hospitals, and these participants mostly employed automated instrument and professional operators.

Study conducted by Holland et al. (2) examined the mean TAT (received to verified) and percentage outliers ( $>30$ minutes: $C B C,>40$ minutes: chemistry measurements, $>60$ minutes: troponin $\mathrm{I},>30$ minutes: urinalysis) in ED in 11 community hospitals. They observed that the average length of stay (LOS) in the ED correlated significantly with the percentage of the total laboratory outliers $\left(R^{2}\right.$ $=0.75 ; \mathrm{P}<0.01)$ and to a lesser extent the TAT means $\left(R^{2}=0.66 ; P<0.01\right)(2)$. CAP Q-Probes study, by Steindel and Novis examined order to verification times of the urgent samples from the ED or ICU (12). They used 70 minute TAT to define outliers (12). Major areas in which delays occurred were test ordering, 30\%; analytical phase, $28 \%$; collection of the specimen, $27 \%$; post-analytic phase, $2 \%$; and undetermined, $13 \%$ (12). Meanwhile, Manor (13) and Rollo (14) reported that the non-analytical delays, such as transporting and reporting delays, were the main cause of the lagging laboratory TAT. However, we only investigated median intra-TAT and we didn't collect data for pre-analytic TAT or TAT outliers. Namely, there were almost $15 \%$ of the participants who did not have LIS in use, so the intra-laboratory TATs were collected manually. The veracity of these data may be in question. This is one major limitation in this study. Another limitation in our study is that the majority of the participants in this survey were from tertiary hospitals, so the results only could represent laboratories with relatively good performance.

However, there were a large number of laboratories and analytes involved in this survey and the database can provide support for setting suitable median intra-TAT target. As there are no yet any national intra-TAT quality specifications in China at the present, the survey can be really meaningful and conductive. We expect to expand the scope of our survey to the non-analytical areas and conduct a more comprehensive survey in the future. 


\section{Conclusion}

Results in this survey only represented laboratories with relatively good performance. Many laboratories in China had awareness of intra-TAT control and were making effort to reach the target, but still there were numerous laboratories whose median intra-TAT was extremely large. The management of intra-TAT in China needs to be improved. The median intra-TAT varied among different analytes. The intra-TAT of haematology was shorter than that of biochemistry while the intraTAT of blood gas was the shortest. Accredited laboratories were better at intra-TAT monitoring and target setting than non-accredited ones, but there

\section{References}

1. Chauhan KP, Trivedi AP, Patel D, Gami B, Haridas N. Monitoring and Root Cause Analysis of Clinical Biochemistry Turn Around Time at an Academic Hospital. Ind J Clin Biochem 2014;29:505-9. http://dx.doi.org/10.1007/s12291013-0397-x.

2. Holland LL, Smith LL, Blick KE. Reducing laboratory turnaround time outliers can reduce emergency department patient length of stay: an 11-hospital study. Am J Clin Pathol 2005;124:672-4. http://dx.doi.org/10.1309/ E9QPVQ6G2FBVMJ3B.

3. Gelrud J, Burroughs H, Koterwas J. Emergency care center turnaround time-an improvement story. J Healthc Qual 2008;30:31-7. http://dx.doi.org/10.1111/j.1945-1474.2008. tb01125.x.

4. Derlet RW, Richards JR. Overcrowding in the nation's emergency departments: complex causes and disturbing effects. Ann Emerg Med 2000;35:63-8. http://dx.doi.org/10.1016/ S0196-0644(00)70105-3.

5. ISO. Medical laboratories: particular requirements for quality and competence. ISO 15189. Geneva: International Organization for Standardization, 2012.

6. Department of Medical Administration, Ministry of Health of the People's Republic of China. Regulation on clinical laboratory of medical organization. Beijing, China: Science Press, 2006. were no significant differences in median intra-TAT reported by them.

\section{Acknowledgments}

We appreciate those participant laboratories and institutions that attended the EQA schemes for this survey. We also thank Clinet website (www.clinet.com.cn) which gave us computer technology support to establish the network platform for the survey and relevant services.

\section{Potential conflict of interest}

Authors declared funding received the Beijing Natural Science Foundation in 2014 (No.7143182).

7. Department of Medical Administration, Ministry of Health of the People's Republic of China. Evaluation standards for tertiary general hospitals, page 101. Beijing, China: Science Press, 2011.

8. Steindel SJ, Howanitz PJ. Physician satisfaction and emergency department laboratory test turnaround time. Arch Pathol Lab Med 2001;125:863-71.

9. Plebani M, Astion ML, Barth JH, Chen WX, Escuer ML, Miller $W G$, et al. Harmonization of quality indicators in laboratory medicine. A preliminary consensus. Clin Chem Lab Med 2014;52:951-8. http://dx.doi.org/10.1515/cclm-20140142.

10. Zeng $R$, Wang W, Wang ZG. National survey on critical values notification of 599 institutions in China. Clin Chem Lab Med 2013; 51:2099-107. http://dx.doi.org/10.1515/cclm2013-0183.

11. Valenstein PN, Emancipator K. Sensitivity, specificity and reproducibility of four measures of laboratory turnaround time. Am J Clin Patho 1989;91:452-7.

12. Steindel SJ, Novis DA. Using outlier events to monitor test turnaround time. Arch Pathol Lab Med 1999;123:607-14.

13. Manor PG. Turnaround times in the laboratory: a review of the literature. Clin Lab Sci 1999;12:85-9.

14. Rollo JL, Fauser BA. Computers in total quality management. Statistical process control to expedite stats. Arch Pathol Lab Med 1993;117:900-5. 